\title{
The cost implications of continuous glucose monitoring in pregnant women with type 1 diabetes in 3 Canadian provinces: a posthoc cost analysis of the CONCEPTT trial
}

\author{
Rashid J. Ahmed MSc, Amiram Gafni DSc, Eileen K. Hutton PhD, Zheng Jing Hu MSc, \\ J. Johanna Sanchez PhD, Helen R. Murphy MD, Denice S. Feig MD; for the CONCEPTT Collaborative \\ Group*
}

\section{Abstract}

Background: The Continuous Glucose Monitoring in Women with Type 1 Diabetes in Pregnancy Trial (CONCEPTT) found improved health outcomes for mothers and their infants among those randomized to self-monitoring of blood glucose (SMBG) with continuous glucose monitoring (CGM) compared with SMBG alone. In this study, we evaluated whether CGM or standard SMBG was more or less costly from the perspective of a third-party payer.

Methods: We conducted a posthoc analysis of data from the CONCEPTT trial (Mar. 25, 2013, to Mar. 22, 2016). Health care resource data from 215 pregnant women, randomized to CGM or SMBG, were collected from 31 hospitals in 7 countries. We determined resource costs posthoc based on prices from hospitals in 3 Canadian provinces (Ontario, British Columbia, Alberta). The primary outcome was the difference between groups in the mean total cost of care for mother and infant dyads, paid by each government (i.e., the third-party payer) from randomization to hospital discharge (time horizon). The secondary outcome included CGM and SMBG costs not paid by governments (e.g., glucose monitoring devices and supplies).

Results: The mean total cost of care was lower in the CGM group compared with the SMBG group in each province (Ontario: $\$ 13270.25$ v. $\$ 18465.21$, difference in mean total cost [DMT] $-\$ 5194.96,95 \%$ confidence interval [Cl] $-\$ 9841$ to $-\$ 1395$; $\mathrm{BC}$ : $\$ 13480.57$ v. $\$ 18762.17$, DMT $-\$ 5281.60,95 \% \mathrm{Cl}-\$ 9964$ to $-\$ 1382$; Alberta: $\$ 13294.39$ v. $\$ 18674.45, \mathrm{DMT}-\$ 5380.06$, $95 \% \mathrm{Cl}-\$ 10216$ to $-\$ 1490)$. There was no difference in the secondary outcome.

Interpretation: Government health care costs are lower when CGM is paid by the patient, driven by lower costs from reduced use of the neonatal intensive care unit in the CGM group; however, when governments pay for CGM equipment, there is no overall cost difference between CGM and SMBG. Governments should consider paying for CGM, as it results in improved maternal and neonatal outcomes with no added overall cost. Trial registration: ClinicalTrials.gov, no. NCT01788527


he incidence of type 1 diabetes is increasing worldwide. ${ }^{1}$ Improved glycemic control during pregnancy has been shown to reduce maternal and neonatal complications. ${ }^{2}$ Continuous glucose monitoring (CGM) is an emerging technology intended to replace standard selfmonitoring of blood glucose (SMBG) using a glucometer and glucose testing. The most recent Diabetes Canada guideline on diabetes and pregnancy recommended the use of CGM for pregnant patients with type 1 diabetes to minimize maternal and neonatal complications. ${ }^{2}$ Government funding of CGM has recently been suggested for pregnant women with type 1 diabetes in Australia, England and Wales. ${ }^{3-5}$

The Continuous Glucose Monitoring in Women with Type 1 Diabetes in Pregnancy Trial (CONCEPTT) was an international multicentre, open label, randomized controlled trial conducted to determine the effectiveness of CGM compared with SMBG in improving glycemic control during
Competing interests: Rashid Ahmed received grant support from the Centre for Clinical Trial Support, Sunnybrook Research Institute, Toronto, Canada, from a grant funded by the Juvenile Diabetes Research Foundation (JDRF) and grants under the JDRF Canadian Clinical Trial Network. Helen Murphy reports personal fees from Medtronic, Novo Nordsik, Roche and Dexcom. She also reports acting as a board member of the Medtronic European Scientific Advisory Board, all outside the submitted work. Denice Feig reports receiving grant support from the JDRF Canadian Clinical Trials Network and advisory board and speaker fees from Medtronic, outside the submitted work. No other competing interests were declared.

This article has been peer reviewed.

${ }^{*}$ The list of members is provided in Appendix 1, available at www. cmajopen.ca/content/9/2/E627/suppl/DC1.

Correspondence to: Eileen Hutton, huttone @ mcmaster.ca

CMAJ Open 2021. DOI:10.9778/cmajo.20200128 
pregnancy in women with type 1 diabetes. The study is described elsewhere. ${ }^{6}$ Briefly, 325 women with type 1 diabetes (215 pregnant cohort, 110 planning pregnancy cohort) were enrolled in 2 parallel trials between 2013 and 2016 at 31 hospitals in Canada, England, Scotland, Spain, Italy, Ireland and the United States. Participants were randomized to receive SMBG plus CGM (treatment group) or SMBG alone (control group) until birth. The primary outcome for the pregnant cohort, change in glycosylated hemoglobin $\left(\mathrm{HbA}_{\mathrm{lc}}\right)$ from randomization to 34 weeks' gestation, improved in the CGM group. Participants in the CGM group spent more time in the target glucose range $(3.5-7.8 \mathrm{mmol} / \mathrm{L})$ and less time in the hyperglycemic range (> $7.8 \mathrm{mmol} / \mathrm{L})$. The CGM group had improved neonatal health outcomes, with fewer infants who were large for gestational age, fewer admissions to the neonatal intensive care unit (NICU) longer than 24 hours, fewer incidences of neonatal hypoglycemia and shorter lengths of hospital stay.

A recent budget impact modelling study using CONCEPTT data from the perspective of the National Health Services in England determined that routine use of CGM would result in substantial cost savings, mainly through reductions in NICU admissions and shorter durations of NICU care. ${ }^{7}$ However, costs are different in Canada, and no province currently pays for CGM supplies. The cost implications of using CGM compared with SMBG for health care systems funded by the Canadian government are not yet known, and thus were evaluated using CONCEPTT data. The aim of this study was to determine whether CGM was more or less costly than SMBG from the perspective of a third-party payer, using CONCEPTT trial data. We evaluated costs in the context of 3 Canadian provinces, Ontario, British Columbia and Alberta, where the health care system is funded and managed by these provincial governments.

\section{Methods}

\section{Study design, setting and participants}

We conducted a posthoc cost analysis of data from the CONCEPTT trial's pregnant cohort, excluding patients without complete outcome data. Patients were randomized into the trial from Mar. 25, 2013, to Mar. 22, 2016. We sought to determine whether the mean total cost of care per mother/infant dyad was more or less costly for those randomized to the CGM group compared with the SMBG study group. Specifically, we determined the cost of care for pregnant CONCEPTT participants if care had been provided in Ontario, BC or Alberta, Canada.

We used a third-party payer perspective as health care in Canada is publicly funded through the Ministry of Health in each province. In these provincial health care systems, patients do not pay for most health care services, but would be responsible for paying for CGM devices, CGM sensors, glucometers and glucose testing strips. Collectively, these 3 provinces represent $63 \%$ (21.84 million people) of Canada's population $^{8}$ and $62 \%$ of the country's total public sector health expenditure. ${ }^{9}$ All have similarly structured health care systems. Evaluating costs in 3 provinces provides robustness to cost comparisons and acts as a sensitivity analysis, and given the representativeness of the population covered across these provinces, also provides generalizability.

In the CONCEPTT trial, continuous glucose monitors and sensors were provided at no cost to participants. Participants in both CGM and SMBG groups used their own purchased glucometers and glucose testing strips. All international centres in the trial were carefully screened and chosen by the central coordinating site at Sunnybrook Research Institute, Toronto, to have facilities, conditions and medical practices similar to those in Canada.

\section{Outcomes}

The primary outcome was the difference in the mean total cost of 18 health care services consumed by mother/infant dyads in the CGM group compared with the SMBG group in each province. The secondary outcome was the same as the primary cost outcome, but included the additional costs of CGMs, sensors, glucometers and glucose testing strips, assumed to be paid by the government at retail prices. To better understand results, we planned an explanatory analysis of cost drivers. The time horizon for health outcomes and costs was from trial randomization until primary hospital discharge for mothers and infants. All costs are in 2013 Canadian dollars, the first year of CONCEPTT trial recruitment.

\section{Data sources}

\section{Resource use}

In the CONCEPTT trial, we collected health care resource utilization data prospectively for mothers and infants from randomization until maternal and neonatal hospital discharge after birth. We measured 18 health care resources, including unscheduled contacts, physician services, hospital ward stays, and the number of CGM devices, CGM sensors, glucometers and glucose testing strips estimated to have been consumed from randomization to delivery. We define unscheduled contacts as all patient visits with the nurse, doctor, research staff or CGM helpline that were not already planned in the trial schedule of study visits, including clinic visits or appointments via phone, email or text.

The total maternal hospital length of stay for delivery was available, but not by hospital ward type, which varies substantially in cost per hour. We estimated duration of use of operating rooms and of labour and delivery wards before and after the actual birth time using the mean ward duration by parity and delivery mode observed in another obstetric trial. ${ }^{10} \mathrm{We}$ increased estimates of postnatal labour and delivery ward duration to 24 hours after delivery, per Canadian clinical guidelines for cases where preeclampsia was adjudicated or for cases with hypertensive symptoms during pregnancy or after delivery. ${ }^{11,12} \mathrm{We}$ ascribed the time between hospital admission and start of labour to the antenatal ward, the time from start of labour to estimated labour and delivery discharge to the labour and delivery ward, and the time between estimated discharge to actual hospital discharge to the postnatal ward. 
Data from the CONCEPTT trial indicated only that infants were admitted to high-level neonatal care. For costing purposes, these cases were categorized into level 3 intensive (NICU 3) or level 2 intermediate (NICU 2) neonatal ward care. Admission to NICU 3 care was attributed to babies with reported conditions consistent with provincial admission guidelines and billing definitions, including any of the following: requiring artificial ventilation, full intensive monitoring and parenteral alimentation; ${ }^{13-15}$ birth at less than 32 weeks, birth weight less than $1500 \mathrm{~g}$ or positive pressure ventilation; or any of 10 possible serious neonatal morbidities requiring NICU 3 admission determined from another similar cost analysis study (i.e., patent ductus arteriosus, early onset sepsis within first 48 hours of life, bronchopulmonary dysplasia, retinopathy of prematurity stage $>2$, intraventricular hemorrhage, cystic periventricular leukomalacia, hypoxic-ischemic encephalopathy, necrotizing enterocolitis, laparotomy or thoracotomy). ${ }^{16}$ Using these parameters, 2 independent neonatologists, not associated with the CONCEPT trial and masked to treatment group and hospital length of stay, adjudicated cases admitted to high-level care to either intensive NICU level 3 or to NICU level 2.

\section{Costs}

We determined the cost of physician services in Ontario, BC and Alberta using 2013 provincial government health insurance plan schedules of medical benefits. ${ }^{13-15}$ All services involved a flat or time-dependent fee component, and a premium depending on time of day and day of the week (i.e., for evening, night and weekend calls). Given variation in fees by time, an average unit cost per patient was calculated to illustrate the unit costs applied in each province (Appendix 2, www.cmajopen.ca/content/9/2/E627/supp1/DC1). We determined costs for time spent in hospital wards using unit costs by ward type (antenatal, labour and delivery, operating, postnatal, NICU 2 and NICU 3) and delivery mode, determined for a similar perinatal cost study in $2002^{17}$ and increased by $20.5 \%$ to 2013 prices using the health care commodity group of the Canadian Consumer Price Index. ${ }^{18}$ Ward unit costs were not province specific, but were derived ${ }^{17}$ from 4 teaching and 3 community hospitals in each of the included provinces, combined into 1 midpoint unit cost per hour by ward (Appendix 3, www.cmajopen.ca/content/9/2/E627/supp1/DC1). Further definitions and assumptions for physician services and ward durations are included in Appendix 4, www.cmajopen. $\mathrm{ca} /$ content/9/2/E627/supp1/DC1. Our methods used to derive and apply hospital ward unit costs are summarized in Appendix 5, www.cmajopen.ca/content/9/2/E627/suppl/DC1.

We obtained unit costs for CGM devices and CGM sensors from Medtronic Canada and unit costs for glucometers and glucose testing strips from Ascensia (formerly Bayer) Diabetes Care Canada. Private and retail market costs from 2013 were available, but insurance or government market costs were not; all costs were indicated to be the same in each province (Appendix 6, www.cmajopen.ca/content/9/2/E627/suppl/ DC1). We included costs for 1 CGM and 1 glucometer per participant in the CGM group, and 1 glucometer per partici- pant in the SMBG group. The trial protocol indicated the use of 1 CGM sensor every 6 days, and 7 glucose testing strips per day in both study groups. We estimated total consumption and costs of these 2 resources on an intention-to-treat basis, from randomization to delivery dates or times for each participant.

\section{Statistical analysis}

Costing involved multiplying actual resources consumed by each trial participant by their respective unit costs in each province to determine the total cost of each of 18 physician services and hospital ward stays, and overall total cost for each participant. We used an intention-to-treat approach for our analysis, whereby mother/infant dyads were included in the arm to which they were randomized. Statistical analysis used a frequentist approach. We assumed that the mean total costs per mother/infant dyad in each arm of the trial were not normally distributed.

Using R statistical software version 3.5.1, we estimated the standard errors and $95 \%$ confidence intervals (CIs) of the difference in the mean total cost per mother/infant dyad between groups using the bias-corrected and accelerated (BCA) bootstrap percentile method with 2000 iterations. ${ }^{19}$ For each province, we estimated the difference in mean total costs and CI for health care services paid by provincial governments (primary outcome) and for health care services paid by the provincial government, including the cost of CGM devices, CGM sensors, glucometers and glucose testing strips currently paid by the provincial governments (secondary outcome). We did not account for any other source of uncertainty than the difference in mean total costs between mother/ infant dyads in each province. We analyzed each province separately. All health care resources and unit costs in each province were fixed for each mother/infant dyad with no error parameters (e.g., physician fee for cesarean delivery, physician premium for time of day or week, number of hours on labour and delivery ward, number of clinic visits, number of hours in NICU level 3).

To show what was driving costs between the CGM and SMBG groups, we determined the absolute difference in mean cost between groups for each service and ward, and ranked the cost differences in descending order of magnitude. For the top unique cost drivers, where parameters were similarly estimated, we tested their significance assuming no distribution and using an achieved significance level of the BCA method, and calculated $95 \%$ CIs using bootstrapping with 2000 iterations.

We conducted an ad hoc analysis of the cost of all health care services paid by provincial governments, including glucometers and testing strips, to estimate the maximum mean cost of CGM devices and sensors that could be afforded by government while still maintaining a significantly less expensive CGM group cost.

\section{Ethics approval}

The CONCEPTT study protocol ${ }^{20}$ was approved by the Health Research Authority, East of England Research Ethics Committee (12/EE/0310) for all study sites in the United 
Kingdom. All other centres obtained ethics approval. Participants provided written informed consent before enrolment. Mount Sinai Hospital Research Ethics Board (12-0037-A) approved this posthoc cost analysis.

\section{Results}

There were 215 patients in the pregnancy cohort of the original trial. We excluded 13 patients without complete outcome data for costing from randomization to delivery (9 cases of spontaneous abortion or termination $\leq 19$ weeks and 4 cases lost to follow-up). Our cost analysis therefore included 202 participants, with 100 mother/infant dyads in the CGM group and 102 mother/infant dyads in the SMBG control group.

\section{Resource use}

Service use varied between groups (Table 1). The CGM group had more spontaneous vaginal deliveries, fewer elective or emergency cesarean deliveries and a shorter maternal hospital length of stay for delivery, including shorter antenatal ward duration, compared with the SMBG group. The CGM group had $36.7 \%$ fewer NICU level 2 admissions, with $65.2 \%$ less time spent in NICU 2; the CGM group also had $26.7 \%$ fewer NICU level 3 admissions, with $41.7 \%$ less time spent in NICU 3. There were $47.3 \%$ more unscheduled contacts in the CGM group with the nurse, doctor, research staff or CGM helpline, mostly for reasons involving the CGM device, for both diabetes management and CGM reasons or for other unspecified reasons.

\section{Costs}

The mean cost in each group represents the total cost incurred for services or wards used by all mothers and their infants in that group, divided by the total number of women in the study group (Appendix 7, www.cmajopen.ca/content/ 9/2/E627/suppl/DC1). In each province, mean costs were about $\$ 5300$ lower (-\$5194.96 in Ontario, $-\$ 5281.60$ in BC and $-\$ 5380.06$ in Alberta) for the CGM group than the SMBG group (Table 2).

When we included costs for CGM devices, CGM sensors, glucometers and glucose testing strips at private market rates in the total costs paid for by provincial governments, the mean cost of all services and wards was not significantly different between CGM and SMBG groups (Table 2).

\section{Cost drivers}

Health care resources with the greatest difference in mean cost between study groups (i.e., cost drivers) are shown in Appendix 8, www.cmajopen.ca/content/9/2/E627/suppl/DC1. The total cost of CGM devices, CGM sensors, glucometers and glucose testing strips in the CGM group was the biggest cost driver when paid by the government. Costs associated with the use of the NICU level 2 ward (ranked no. 5 cost driver in all provinces) and NICU level 2 physicians (ranked no. 11 in all provinces) were also significant cost drivers that favoured the lower cost CGM group.

\section{Ad hoc analysis}

In our ad hoc analysis, we included the cost of glucometers and glucose testing strips for both CGM and SMBG groups, but excluded the cost of CGM devices and CGM sensors to determine the combined maximum cost of CGM devices and CGM sensors to remain less expensive than the SMBG group. The maximum mean total cost of CGM devices and CGM sensors to remain less expensive than the SMBG group for government payers was about $\$ 1400$ per patient ( $\$ 1372$ in Ontario, \$1386 in BC and \$1473 in Alberta), considering the time from randomization to delivery (Table 2). This cost is represented by the upper CI level of the difference in the mean total cost between groups.

\section{Interpretation}

Using data from a large, multicentred randomized controlled trial that measured resources prospectively with detailed follow-up, we showed that, for government payers, the mean costs for overall services and hospital ward use was less expensive in the CGM group than the SMBG group. The upper and lower limits of the $95 \%$ CIs provide a useful estimation of maximum and minimum costs to governments. For example, when no CGM devices and consumables are paid by governments, the overall mean cost savings for the CGM group is $\$ 5195$ in Ontario but could be as much as \$9841 or as little as $\$ 1395$. Fewer infants spent time in NICU level 2 in the CGM group, significantly lowering overall costs. If provincial governments paid for CGM and SMBG devices and consumables at the 2013 private market rates, the mean cost of care was not different between groups; however, CGM resulted in improved health outcomes for mothers and their infants. ${ }^{6}$ For example, the $95 \%$ CI showed that the CGM group could save the Ontario government as much as $\$ 6424$ or cost up to $\$ 1942$ more than the SMBG group. Providing CGMs and sensors increased costs in the CGM group.

Overall, when governments pay for CGM, mothers and infants can reap the important clinical benefits of this technology, as observed in the main efficacy trial, ${ }^{6}$ at no increased cost to government. Benefits of CGM observed in the trial included improved maternal glucose control, lower total length of hospital stay, fewer cesarean births, shorter maternal hospital stay for birth, fewer large-for-gestational-age infants, less neonatal hypoglycemia, fewer and shorter NICU 2-3 admissions and lower NICU 2 costs. The CGM group had $47 \%$ more unscheduled contacts, more maternal antenatal hospitalizations and more assessments in the obstetrical day unit. The higher number of unscheduled contacts in the CGM group may reflect initial challenges of integrating CGM use into daily diabetes management during early pregnancy. With newer, more reliable, user-friendly CGM sensors, these unscheduled contacts may be less frequent. Downstream clinical and cost benefits for infants of mothers who used CGM and avoided more birth complications and NICU admissions were not measured in our posthoc cost analysis, but may represent further cost savings to governments. 
Table 1 (part 1 of 2): Health care resources consumed by pregnant women with type 1 diabetes and their infants from CONCEPTT trial randomization until hospital discharge after delivery

\begin{tabular}{|c|c|c|c|c|}
\hline \multirow[b]{2}{*}{ Health care resource } & \multicolumn{2}{|c|}{ CGM } & \multicolumn{2}{|c|}{ SMBG } \\
\hline & $\begin{array}{l}\text { No. of } \\
\text { resources* }\end{array}$ & $\begin{array}{c}\text { No. of } \\
\text { mother/ } \\
\text { infant dyads } \\
n=100\end{array}$ & $\begin{array}{l}\text { No. of } \\
\text { resources* }\end{array}$ & $\begin{array}{c}\text { No. of } \\
\text { mother/ } \\
\text { infant dyads } \\
n=102\end{array}$ \\
\hline \multicolumn{5}{|l|}{ Antenatal assessments or visits } \\
\hline Total unscheduled contacts $†$ & 1510 & 96 & 1025 & 91 \\
\hline For diabetes management & 844 & 89 & 858 & 87 \\
\hline For CGM issue & 211 & 63 & 8 & 6 \\
\hline For diabetes and CGM issues & 269 & 42 & 25 & 14 \\
\hline For other reasons not specified & 186 & 51 & 134 & 46 \\
\hline \multicolumn{5}{|l|}{$\begin{array}{l}\text { Maternal antenatal hospitalizations } \\
\geq 24 \mathrm{~h} \text { not for delivery }\end{array}$} \\
\hline No. of admissions & 25 & 22 & 21 & 17 \\
\hline Total length of hospital stay, $d$ & 54 & & 42 & \\
\hline \multicolumn{5}{|l|}{ Maternal obstetrical day unit } \\
\hline No. of visits & 9 & 7 & 8 & 8 \\
\hline Total length of visits (assumed $6 \mathrm{~h} / \mathrm{visit}$ ), $\mathrm{h}$ & 54 & & 48 & \\
\hline \multicolumn{5}{|l|}{ Delivery } \\
\hline Pregnancy termination $\geq 20 \mathrm{wk}$ & 0 & 0 & 1 & 1 \\
\hline Stillbirth & 0 & 0 & 1 & 1 \\
\hline Inductions (assumed 1 induction per participant) & 49 & 49 & 42 & 42 \\
\hline $\begin{array}{l}\text { Spontaneous vaginal delivery } \\
\text { (excludes } 1 \text { termination) }\end{array}$ & 28 & 28 & 18 & 18 \\
\hline Operative vaginal delivery (excluding 1 stillbirth) & 9 & 9 & 8 & 8 \\
\hline Elective or planned cesarean delivery & 26 & 26 & 30 & 30 \\
\hline Emergency or unplanned cesarean delivery & 37 & 37 & 44 & 44 \\
\hline \multicolumn{5}{|l|}{ Hospital length of stay for delivery } \\
\hline $\begin{array}{l}\text { Total maternal hospital length of stay for delivery, } d \\
\text { (h) }\end{array}$ & $\begin{array}{c}474.9 \\
(11396.8)\end{array}$ & 100 & $\begin{array}{c}560.9 \\
(13461.4)\end{array}$ & 102 \\
\hline Total antenatal ward duration $\ddagger, \mathrm{h}$ & 2306.0 & 100 & 4078.1 & 102 \\
\hline $\begin{array}{l}\text { Participants with hypertensive symptoms or } \\
\text { preeclampsia }\end{array}$ & & 18 & & 29 \\
\hline Total labour and delivery ward duration, $\mathrm{h}$ & 1301.3 & 100 & 1600.8 & 102 \\
\hline Total operating room ward duration§, $\mathrm{h}$ & 93.8 & 72 & 108.4 & 84 \\
\hline Total postpartum ward durationף, $\mathrm{h}$ & 7789.6 & 100 & 7782.5 & 102 \\
\hline \multicolumn{5}{|l|}{ NICU } \\
\hline $\begin{array}{l}\text { Total length of stay in high level NICU for any high } \\
\text { level NICU admission, } d(h)\end{array}$ & $\begin{array}{c}180.0 \\
(4320.6)\end{array}$ & 30 & $\begin{array}{c}391.6 \\
(9398.0)\end{array}$ & 45 \\
\hline $\begin{array}{l}\text { Total length of stay in high level NICU for physician } \\
\text { care, } d\end{array}$ & 208 & 30 & 430 & 45 \\
\hline Adjudicated NICU Level 2 physician care, $d$ & 88 & 19 & 230 & 30 \\
\hline Adjudicated NICU Level 3 physician care, d & 120 & 11 & 200 & 15 \\
\hline NICU level 2 hospital ward duration, d (h) & $\begin{array}{c}71.3 \\
(1711.7)\end{array}$ & 19 & $\begin{array}{c}205.1 \\
(4922.5)\end{array}$ & 30 \\
\hline NICU Level 3 hospital ward duration, d (h) & $\begin{array}{c}108.7 \\
(2608.9)\end{array}$ & 11 & $\begin{array}{c}186.5 \\
(4475.5)\end{array}$ & 15 \\
\hline
\end{tabular}




\begin{tabular}{|c|c|c|c|c|}
\hline \multirow[b]{2}{*}{ Health care resource } & \multicolumn{2}{|c|}{ CGM } & \multicolumn{2}{|c|}{ SMBG } \\
\hline & $\begin{array}{l}\text { No. of } \\
\text { resources* }\end{array}$ & $\begin{array}{c}\text { No. of } \\
\text { mother/ } \\
\text { infant dyads } \\
n=100\end{array}$ & $\begin{array}{l}\text { No. of } \\
\text { resources* }\end{array}$ & $\begin{array}{c}\text { No. of } \\
\text { mother/ } \\
\text { infant dyads } \\
n=102\end{array}$ \\
\hline \multicolumn{5}{|l|}{ CGM and SMBG usage ${ }^{\star *}$} \\
\hline \multicolumn{5}{|l|}{ No. of days used } \\
\hline Total, d & 18511.2 & 100 & 18238.6 & 102 \\
\hline Per patient, mean \pm SD & $185.1 \pm 17.1$ & & $178.8 \pm 20.1$ & \\
\hline \multicolumn{5}{|l|}{ No. of patients using Medtronic CGM devices } \\
\hline Total no. of Medtronic CGM devices & 42 & 42 & NA & NA \\
\hline Medtronic Pump VEO & 30 & 30 & NA & NA \\
\hline Medtronic Veo Kit Pump & 10 & 10 & NA & NA \\
\hline Medtronic Pump 640G & 2 & 2 & NA & NA \\
\hline No. of patients using Guardian CGM devices & 58 & 58 & NA & NA \\
\hline No. of CGM sensors used (estimated) & & & & NA \\
\hline Total & 3134 & 100 & NA & NA \\
\hline Per patient, mean \pm SD & $31.3 \pm 2.9$ & & NA & NA \\
\hline Total no. of glucometers used (estimated) & 100 & 100 & 102 & 102 \\
\hline \multicolumn{5}{|l|}{ No. of SMBG strips used (estimated) } \\
\hline Total & 129630 & 100 & 127722 & 102 \\
\hline Per patient, mean \pm SD & $1296.3 \pm 119.5$ & & $1252.2 \pm 140.7$ & \\
\hline \multicolumn{5}{|c|}{ 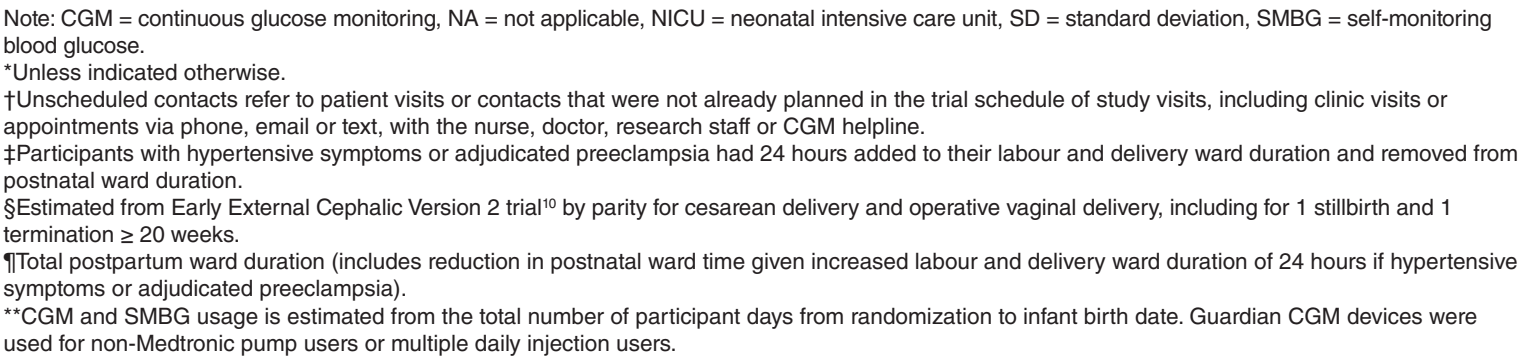 } \\
\hline
\end{tabular}

Provincial governments in Canada could pay up to $\$ 1372$ on CGM devices and sensors and still save money. Providing CGMs for pregnant patients with type 1 diabetes would align care with the 2018 Diabetes Canada guideline. ${ }^{2}$ This study supports recent suggestions to provincial governments for public reimbursement of CGMs for these patients to improve maternal and neonatal outcomes. ${ }^{3-5}$

This posthoc analysis provides clinicians and policy-makers with a Canadian comparison of the cost implications of CGM and SMBG technologies at private market rates for pregnant patients with type 1 diabetes and their infants. A recent budget impact modelling study from the perspective of the National Health Services in England determined that the routine use of CGM would result in substantial cost savings to government, mainly through reductions in the number and duration of NICU admissions. ${ }^{7}$ However, we found costs were equivalent when Canadian provincial governments paid for CGMs. Differences may be because of higher NICU costs in the UK or because the UK study used discounted government CGM prices, whereas we used retail prices available to patients. Evaluating the clinical and cost effectiveness of newer, factory-calibrated CGMs that have improved accuracy and longer sensor duration, with longer follow-up study periods to assess any downstream impact of neonatal outcomes on health care costs, would be informative.

\section{Limitations}

Although we obtained unit costs from 3 Canadian provinces with detailed fee structures, resulting in reliable findings regarding the cost of care for pregnant patients with type 1 diabetes, whether using CGM or SMBG, our approach has some inherent limitations. We scaled ward unit costs from 2002 using health commodity inflation to match 2013 CONCEPTT trial data, but scaled costs may not reflect actual ward costs in 2013. It is possible that our NICU level 3 ward unit cost of $\$ 107.00$ per hour may be lower than that required when caring 


\begin{tabular}{|c|c|c|c|c|c|c|c|c|}
\hline \multirow[b]{2}{*}{ Analysis* } & \multirow[b]{2}{*}{ Province } & \multicolumn{2}{|c|}{$\begin{array}{c}\text { CGM } \\
n=100 \text { mother/infant } \\
\text { dyads }\end{array}$} & \multicolumn{2}{|c|}{$\begin{array}{c}\text { SMBG } \\
n=102 \text { mother/infant } \\
\text { dyads }\end{array}$} & \multicolumn{3}{|c|}{ Difference between CGM and SMBG } \\
\hline & & Mean, \$ & SEM, \$ & Mean, \$ & SEM, \$ & Mean, \$ & SEM, \$ & $95 \% \mathrm{Clt}, \$$ \\
\hline \multirow{3}{*}{$\begin{array}{l}\text { Primary } \\
\text { outcome: total } \\
\text { costs } \\
\text { excluding } \\
\text { glucose } \\
\text { monitoring }\end{array}$} & Ontario & 13270.25 & 1122.61 & 18465.21 & 1758.01 & -5194.96 & 2112.07 & -9841 to -1395 \\
\hline & $\begin{array}{l}\text { British } \\
\text { Columbia }\end{array}$ & 13480.57 & 1154.21 & 18762.17 & 1786.67 & -5281.60 & 2154.34 & -9964 to -1382 \\
\hline & Alberta & 13294.39 & 1141.15 & 18674.45 & 1808.81 & -5380.06 & 2165.35 & -10216 to -1490 \\
\hline \multirow{3}{*}{$\begin{array}{l}\text { Secondary } \\
\text { outcome: total } \\
\text { costs } \\
\text { including } \\
\text { glucose } \\
\text { monitoring }\end{array}$} & Ontario & 17881.01 & 1107.80 & 19699.65 & 1752.10 & -1818.64 & 2099.14 & -6424 to 1942 \\
\hline & $\begin{array}{l}\text { British } \\
\text { Columbia }\end{array}$ & 18091.32 & 1139.41 & 19996.61 & 1780.73 & -1905.29 & 2141.33 & -6588 to 1957 \\
\hline & Alberta & 17905.15 & 1126.42 & 19908.89 & 1802.87 & -2003.74 & 2152.47 & -6747 to 1844 \\
\hline \multirow{3}{*}{$\begin{array}{l}\text { Ad hoc } \\
\text { analysis: } \\
\text { maximum } \\
\text { costs of CGM } \\
\text { to be }<\text { SMBG } \\
\text { costs }\end{array}$} & Ontario & 14546.61 & 1118.35 & 19699.65 & 1752.10 & -5153.04 & 2102.01 & -9801 to -1372 \\
\hline & $\begin{array}{l}\text { British } \\
\text { Columbia }\end{array}$ & 14756.92 & 1149.96 & 19996.61 & 1780.73 & -5239.69 & 2145.74 & -9961 to -1386 \\
\hline & Alberta & 14570.75 & 1136.89 & 19908.89 & 1802.87 & -5338.14 & 2155.59 & -10152 to -1473 \\
\hline \multicolumn{9}{|c|}{$\begin{array}{l}\text { Note: } \mathrm{BCA}=\text { bias-corrected and accelerated, CGM = continuous glucose monitoring, Cl = confidence interval, } \mathrm{SEM}=\text { standard error of the mean, } \mathrm{SMBG}= \\
\text { self-monitoring blood glucose. } \\
\text { *The primary outcome is the total cost of all services, excluding cost of CGM devices, CGM sensors, glucometers and SMBG strips. The secondary outcome is the } \\
\text { total cost of all services, including cost of CGM devices, CGM sensors, glucometers and SMBG strips. The ad hoc analysis estimates the maximum total cost per } \\
\text { patient (including cost of CGM devices, CGM sensors, glucometers and SMBG strips) for CGM to remain significantly cheaper than SMBG during type } 1 \text { diabetes } \\
\text { pregnancy. Negative value favours less costly CGM group. } \\
\text { †The } 95 \% \text { Cls were estimated using the BCA method. }\end{array}$} \\
\hline
\end{tabular}

for infants of patients with type 1 diabetes. The resources consumed in the trial may have differed from those which would have been consumed in the actual Canadian context, although any potential differences cannot be easily determined. Nonetheless, we applied estimates to both groups equally. We may have mitigated errors by using ward duration estimates from another trial, Canadian clinical and provincial admission guidelines, billing definitions and masked, independent adjudication of high-level neonatal care cases. The CONCEPTT trial was powered for clinical rather than cost outcomes, which typically require larger sample sizes because of large variances and positively skewed distributions of costs. Including only Canadian patients from the main trial in our study would have resulted in an insufficient sample size for our cost study and may have led to subgroup analysis bias of a randomized controlled trial. We did not have government prices for CGM devices, which may have lowered our overall calculated costs. Future studies should use a longer time horizon to establish the cost to health care systems incurred after delivery. A societal perspective, including costs to the patient, would also be useful to evaluate in the design of any future trial of CGM use by pregnant patients with type 1 diabetes.

\section{Conclusion}

This study shows an approach to analyze costs and clinical effectiveness to determine the appropriateness and affordability of adopting CGM technology for pregnant patients with type 1 diabetes. When patients pay for both technologies, CGM is less expensive than SMBG to government health care payers, and confers substantial clinical benefit for mothers and their infants, particularly reduced admissions to NICU level 2 and associated costs. If governments pay for up to $\$ 1372$ for CGMs and sensors, they incur no additional overall costs compared with SMBG, and improve outcomes for patients and their babies. Governments should consider paying for CGMs to improve maternal and neonatal outcomes, at no added overall cost.

\section{References}

1. DIAMOND Project Group. Incidence and trends of childhood type 1 diabetes worldwide 1990-1999. Diabet Med 2006;23:857-66.

2. Diabetes Canada Clinical Practice Guidelines Expert Committee; Feig DS, Berger H, Donovan L, et al. Diabetes and pregnancy. Can 7 Diabetes 2018;42(Suppl 1):S255-82.

3. National Diabetes Services Scheme (NDSS). Canberra (AU): Australian Government Department of Health; updated 2021 Jan. 4. Available: www1.health. gov.au/internet/main/publishing.nsf/Content/health-pbs-healthpro-cgm.htm (accessed 2020 Apr. 11).

4. VICTORY for pregnant women with type 1 diabetes: wearable medical tech to be provided by NHS England [news release]. London (UK): Juvenile Diabetes Research Foundation (JDRF); 2019 Jan. 7. Available: https://jdrf.org.uk/news/ pregnant-women-in-england-with-type-1-diabetes-to-receive-wearable-medical -tech-on-nhs/ (accessed 2020 Apr. 11).

5. Health Technology Wales (HTW) Guidance 012 (September 2019): continuous glucose monitoring in pregnant women with type 1 diabetes. Cardiff (UK): Health Technology Wales (HTW); 2019. Available: www.healthtechnology.wales/ wp-content/uploads/2019/10/GUI012-Continuous-glucose-monitoring-in 
-pregnant-women-with-type-1-diabetes-English-3.pdf (accessed 2020 Apr. 11). 6. Feig DS, Donovan LE, Corcoy R, et al.; CONCEPTT Collaborative Group. Continuous glucose monitoring in pregnant women with type 1 diabetes (CONCEPTT): a multicentre international randomised controlled trial. Lancet 2017;390:2347-59.

7. Murphy HR, Feig DS, Sanchez JJ, et al.; CONCEPTT Collaborative Group. Modelling potential cost savings from use of real-time continuous glucose monitoring in pregnant women with type 1 diabetes. Diabet Med 2019; 36:1652-8.

8. Canada's total population estimates, 2013. Ottawa: Statistics Canada; 2013. Available: www150.statcan.gc.ca/n1/en/daily-quotidien/130926/dq130926a-eng. pdf? st=ilGJxDFX (accessed 2020 Apr. 11).

9. Total health expenditure by use of funs. In: National Health Expenditure Trends, 1975 to 2013. Ottawa: Canadian Institute for Health Information; 2014. Available: https://secure.cihi.ca/free_products/3.0_TotalHealthExpenditureFund sEN.pdf (accessed 2020 Apr. 11).

10. Ahmed RJ, Gafni A, Hutton EK; Early ECV2 Trial Collaborative Group. The cost implications in Ontario, Alberta and British Columbia of early versus delayed external cephalic version in the Early External Cephalic Version 2 (EECV2) trial. 7 Obstet Gynaecol Can 2016;38:235-45.e3.

11. Magee LA, Pels A, Helewa M, et al.; SOGC Hypertension Guideline Committee. Diagnosis, evaluation, and management of the hypertensive disorders of pregnancy: executive summary. 7 Obstet Gynaecol Can 2014;36:575-6.

12. Townsend R, O'Brien P, Khalil A. Current best practice in the management of hypertensive disorders in pregnancy. Integr Blood Press Control 2016; 9:79-94.

13. Schedule of benefits - physician services under the Health Insurance Act, revised 2013 Oct. 1 [archived]. Toronto: Ministry of Health and Long-Term Care. Available: http://govdocs.ourontario.ca/node/2924 (accessed 2014 Oct. 1).

14. MSC (Medical Services Commission) Payment Schedule, revised 2013 Nov. 2013 [archived]. Victoria: British Columbia Ministry of Health; 2013.

15. Schedule of medical benefits, health professional fees, medical benefits price list, Alberta Health Care Insurance Plan (applicable to 2013 services). Edmonton: Alberta Health, Government of Alberta; revised 2012 Apr. 1.

16. Ahmed RJ, Gafni A, Hutton EK, et al. The cost implications of less tight versus tight Control of Hypertension in Pregnancy (CHIPS trial). Hypertension 2016;68:1049-55.

17. Palencia R, Gafni A, Hannah ME, et al.; Term Breech Trial Collaborative Group. The costs of planned cesarean versus planned vaginal birth in the Term Breech Trial. CMA7 2006;174:1109-13.

18. Table 4-6: The Consumer Price Index, major components and selected subgroups, Canada, not seasonally adjusted - Health and personal care. Ottawa: Statistics Canada; modified 2015 Nov. 27. Available: www150.statcan.gc.ca/ n1/pub/62-001-x/2013012/t037-eng.htm (accessed 2021 Feb. 11).

19. Efron B, Tibshirani RJ. Better bootstrap confidence intervals. In: An Introduction to the Bootstrap. Boca Raton (FL): Chapman \& Hall/CRC; 1994:178-201.

20. Feig DS, Asztalos E, Corcoy R, et al.; CONCEPTT Collaborative Group. CONCEPTT: continuous glucose monitoring in women with type 1 diabetes in pregnancy trial: a multi-center, multi-national, randomized controlled trial — study protocol. BMC Pregnancy Childbirth 2016;16:167.
Affiliations: Department of Obstetrics and Gynecology, and McMaster Midwifery Research Centre (Ahmed, Hutton), and Centre for Health Economics and Policy Analysis, and the Department of Health Research Methods, Evidence and Impact (formerly, Clinical Epidemiology and Biostatistics) (Gafni), and Department of Health Research Methods, Evidence, and Impact (Hu), McMaster University, Hamilton, Ont.; Sunnybrook Research Institute (Sanchez), Sunnybrook Health Sciences Centre; School of Occupational and Public Health (Sanchez), Ryerson University, Toronto, Ont.; Department of Medicine (Murphy), University of East Anglia, Norwich, UK; Department of Medicine (Feig), University of Toronto, Toronto, Ont.

Contributors: All of the authors contributed to the conception and design of the work, and the acquisition, analysis and interpretation of data. All of the authors drafted the manuscript, revised it critically for important intellectual content, gave final approval of the version to be published and agreed to be accountable for all aspects of the work.

Funding: The CONCEPTT trial was funded by Juvenile Diabetes Research Foundation (JDRF) grants No. 17-2011-533, and grants under the JDRF Canadian Clinical Trial Network), a public-private partnership including JDRF and FedDev Ontario that is supported by JDRF No. 80-2010-585. Medtronic supplied the CGM sensors and CGM systems at reduced cost to the CONCEPTT trial. JDRF, the JDRF Canadian Clinical Trial Network and Medtronic Canada had no role in the study design, data collection, analysis and interpretation, the writing of the report or in the decision to submit the article for publication.

Content licence: This is an Open Access article distributed in accordance with the terms of the Creative Commons Attribution (CC BY-NC-ND 4.0) licence, which permits use, distribution and reproduction in any medium, provided that the original publication is properly cited, the use is noncommercial (i.e., research or educational use), and no modifications or adaptations are made. See: https://creativecommons.org/licenses/by-nc-nd/4.0/

Data sharing: Data are not available for use by other researchers.

Acknowledgements: The authors thank the women with type 1 diabetes who participated in the trial. The authors also acknowledge the invaluable support of the 31 clinical care teams and the CONCEPTT Steering Committee. The authors thank Dr. Jennifer Twiss and Dr. Niels Rochow for their assistance with adjudicating neonatal admissions into level of neonatal care.

Supplemental information: For reviewer comments and the original submission of this manuscript, please see www.cmajopen.ca/content/9/2/ E627/suppl/DC1. 